\title{
A Computed Tomography Analysis of the Success of Spinal Fusion Using Ultra-Low Dose (0.7 mg per Facet) of Recombinant Human Bone Morphogenetic Protein 2 in Multilevel Adult Degenerative Spinal Deformity Surgery
}

\author{
Gabriel Liu, Jun Hao Tan, Changwei Yang, John Ruiz, Hee-Kit Wong \\ University Spine Centre, Department of Orthopaedic Surgery, National University Hospital, National University Health System, Singapore
}

\section{Study Design: Retrospective cohort study.}

Purpose: To report on spinal fusion assessment using computed tomography (CT) after adult spinal deformity (ASD) surgery using ultra-low dose recombinant human bone morphogenetic protein 2 (RhBMP-2).

Overview of Literature: The reported dose of RhBMP-2 needed for successful spinal posterolateral fusion in ASD ranges from 10 to $20 \mathrm{mg}$ per spinal level. This study reports the use of ultra-low dose of RhBMP-2 (0.07 mg per facet) to achieve spinal fusion in multilevel ASD surgery.

Methods: Consecutive patients who underwent ASD surgery using ultra-low dose RhBMP-2 were recruited. Routine postoperative $\mathrm{CT}$ analysis for spinal fusion was performed by two spine surgeons. Inter-observer agreement was calculated for facet fusion (FF) and interbody fusion (IBF) at 6 and 12 months after the procedure.

Results: Six consecutive ASD patients with a mean age of 62 years (28-72 years) were examined. Each patient received a total dose of $12 \mathrm{mg}$ with an average dose of $0.69 \pm 0.2 \mathrm{mg}(0.42-1 \mathrm{mg})$ per single FF and $1.38 \pm 0.44 \mathrm{mg}(0.85-2 \mathrm{mg})$ for IBF. Total $131 \mathrm{FF}$ and $15 \mathrm{IBF}$ were examined in the study, with $88 \mathrm{FFs}$ and nine IBFs being analyzed specifically at 6 months after the surgery. FF and IBF reported by surgeons $A$ and $B$ at 6 months were $97.7 \%$ vs. $91.9 \%$ FF, respectively ( $\kappa=0.95)$ and $100 \%$ vs. $100 \%$ IBF, respectively ( $\kappa=1$ ). Two patients underwent longitudinal follow-up CT at 12 months, and the FF rates reported by surgeons A and B were $100 \%$ vs. $95.8 \%$, respectively ( $\kappa=0.96)$. Five out of nine facet $(56 \%)$ non-unions were identified at the cross-links. The remaining four facet pseudarthrosis were noted at 1-2 spinal levels caudal to the cross-links. At the final clinical follow-up, there was no rod breakage, deformity progression, neurological deficit, or symptom recurrence. The Oswestry Disability Index improved by an average of $32.8 \pm 6.3$, while the mental component summary of the 36-item Short-Form Health Survey improved by an average of 4.7 \pm 2.1 , and physical component summary improved by an average of $10.5 \pm 2.1$.

Conclusions: To our knowledge, this is the first study to report a CT that defined $92 \%-98 \%$ FF and $100 \%$ IBF using the lowest reported dose of RhBMP-2 in multilevel ASD surgery. The use of ultra-low dose RhBMP-2 reduces the RhBMP-2 related complications and healthcare costs.

Keywords: Bone morphogenetic protein; Scoliosis; Spinal fusion; Multidetector computed tomography

Received Oct 26, 2017; Revised Mar 25, 2018; Accepted May 22, 2018

Corresponding author: Gabriel Liu

University Spine Centre, Department of Orthopaedic Surgery, National University Hospital, National University Health System, 1E Kent Ridge Road, Singapore 119228

Tel: +65-92338520, Fax: +65-67780720, E-mail: Gabriel_LIU@nuhs.edu.sg 


\section{Introduction}

Degenerative lumbar scoliosis is observed commonly [14]. We previously reported a $9.1 \%$ prevalence of adult degenerative lumbar scoliosis among a study population of $>7,000$ Asian subjects [5]. Management of these painful, symptomatic adult spinal deformities (ASDs) requires major spinal reconstruction with multilevel spinal decompression and fusion surgery [6].

One of the unfavorable surgical complications of multilevel fusion surgery is pseudarthrosis. Pseudarthrosis is defined as failure of solid spinal fusion one-year after the procedure, and the reported rate of pseudarthrosis ranges from $1 \%$ to $57 \%$ [7-9]. Bone morphogenic proteins (BMPs) were first discovered by Urist [10] in 1965 and were first cloned in 1988 by Wozney et al. [11]. Recombinant human bone morphogenetic protein 2 (RhBMP-2) has demonstrated the ability to stimulate bone formation and enhance, even replace, autogenous bone graft to reduce the rates of pseudarthrosis and achieving spinal fusion [1215].

However, the use of RhBMP-2 involves certain complications. In 2008, the Food and Drug Administration released a public health notification to alert practitioners regarding the risk of soft tissue swelling and airway compromise related to the placement of BMPs in the anterior cervical spine; 38 incidences were reported during a 4-year period $[1,16]$. Others have reported complications, such as heterotopic ossification, radiculitis, seroma formation, osteolysis, and even cancer formation, following the use of RhBMP-2 [16-20]. It is noteworthy that RhBMP-2-related complications appear to be dose dependent $[17,21,22]$. Studies recommended the use of high-dose RhBMP-2 to achieve posterolateral fusion, and the required dosage ranges from 12 to $20 \mathrm{mg}$ per spinal level $[12,13]$.

To the best of our knowledge, few studies have examined the minimal dosage required for successful spinal fusion in ASD. Our study aimed to report the success rates of fusion using computed tomography (CT) analysis for spinal facet and interbody fusion (IBF) after ASD surgery using ultra-low dose RhBMP-2.

\section{Materials and Methods}

This retrospective study included six consecutive ASD patients who had spinal reconstruction surgery using ultra-low dose RhBMP-2 in a National University Hospi-

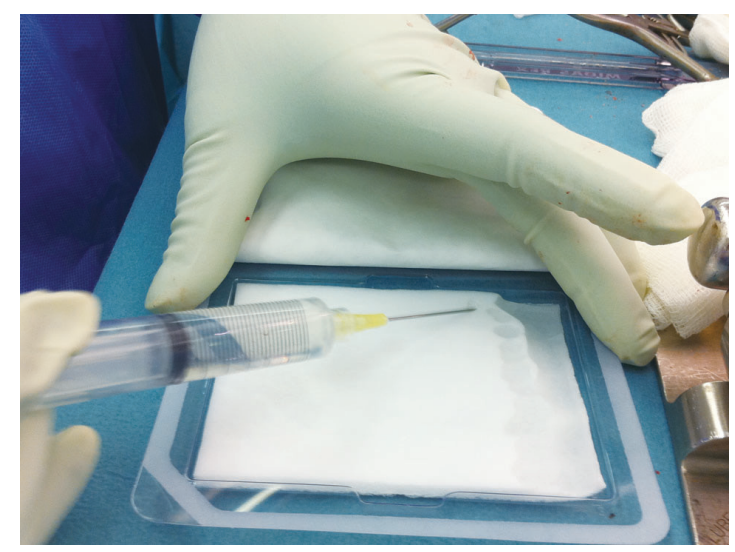

Fig. 1. Recombinant human bone morphogenetic protein 2 injected into absorbable collagen sponge matrix.

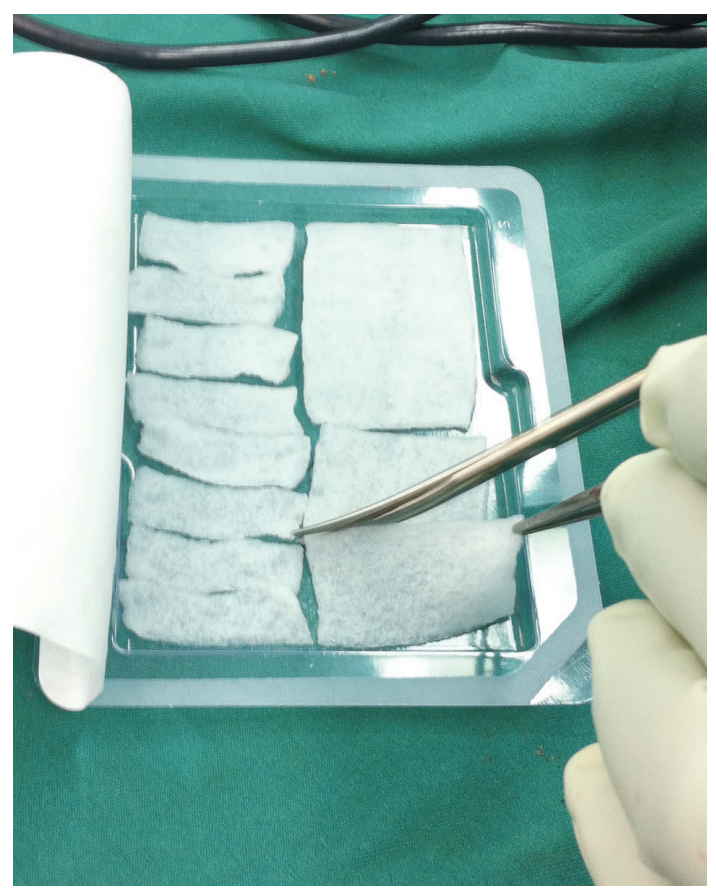

Fig. 2. Cutting into strips.

tal, Singapore. Indications for surgery were degenerative lumbar scoliosis with symptoms of pain and neurogenic claudication. Patients with previous lumbar surgery or a malignancy were excluded. The patients' clinical, surgical, and radiological data were collected for analyses.

IRB approval was given by the National Healthcare Group (Reference 2015/00576). As this was a retrospective study, informed consent was waived.

The prepared RhBMP-2 (Infuse; Medtronic, Memphis, TN, USA) was first evenly soaked onto the absorbable collagen sponge matrix provided by the vendor. The matrix was then cut into identical strips to ensure the desired low 


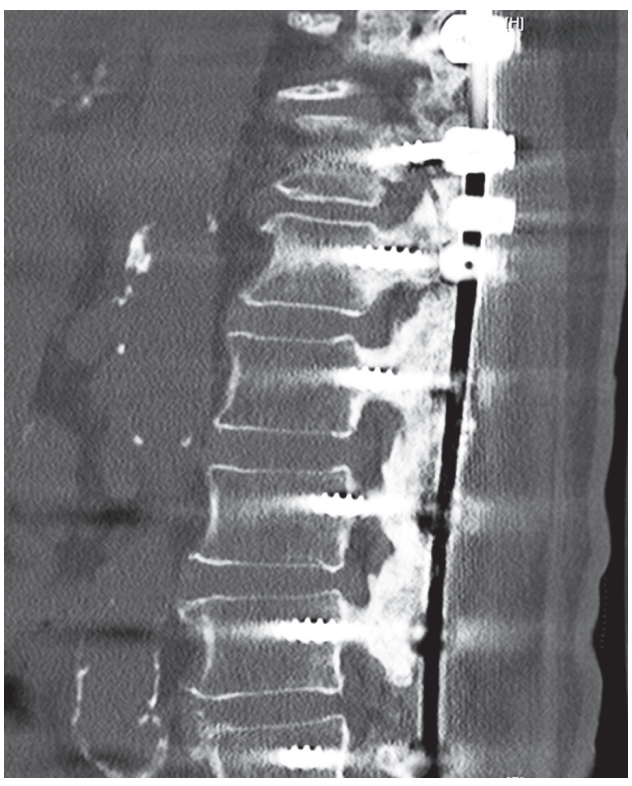

Fig. 3. Computed tomography analysis showing successful facet fusion.

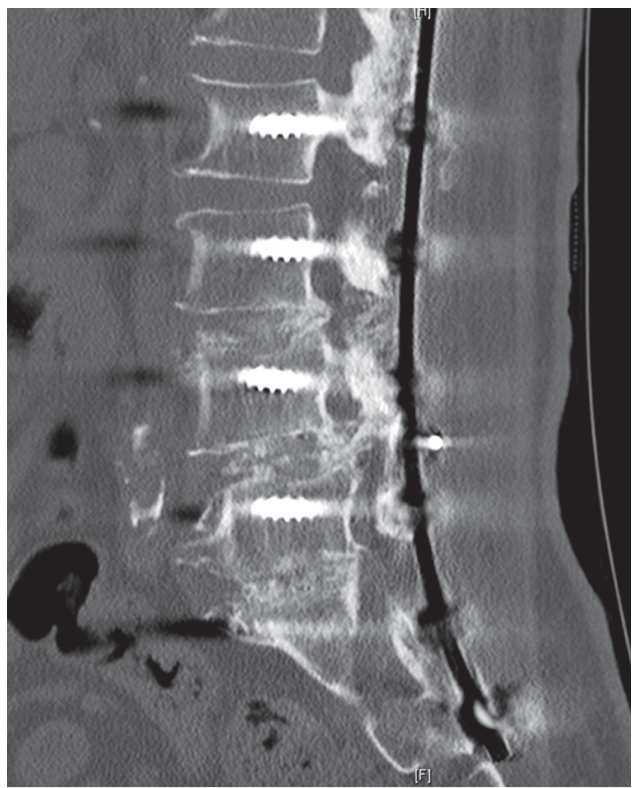

Fig. 4. Computed tomography analysis showing interbody fusion.

dose of RhBMP-2 in each strip (Figs. 1, 2).

For facet fusion (FF), 1 matrix containing $4.2 \mathrm{mg}$ (small kit, Infuse; Medtronic) RhBMP-2 can be cut into six identical strips, each containing $0.7 \mathrm{mg}$ of RhBMP-2. Thereafter, each RhBMP-2 strip was inserted into the decorticated facet and covered with local decorticated bone chips. The remaining local bone graft was then placed underneath the rod over the decorticated lamina to complete the posterolateral fusion.
Table 1. Demographics and clinical details

\begin{tabular}{lc} 
Variable & Mean (range) \\
\hline Age $(\mathrm{yr})$ & $62(28$ to 72$)$ \\
\hline Preoperative Cobb's angle $\left(^{\circ}\right)$ & $25(15$ to 43$)$ \\
\hline C7 sagittal plumbline $(\mathrm{cm})$ & $-8.4(-12$ to 16$)$ \\
\hline Average spinal fusion levels & $11(8$ to 15$)$ \\
\hline Mean operative time (min) & $536(373$ to 704$)$ \\
Intra-operative blood loss $(\mathrm{mL})$ & $975(500$ to 1,800$)$ \\
\hline
\end{tabular}

For the IBF, total $1.38 \mathrm{mg}$ RhBMP-2 was split into two collagen strips, each containing 0.69 mg RhBMP-2. After discectomy and endplate decortication, one strip of 0.69 mg RhBMP-2 was applied into the disc space and covered by sentinel local bone graft. This was followed by interbody polyetheretherketone cage insertion that was then filled with the second collagen strip of $0.69 \mathrm{mg}$ RhBMP-2 and local bone graft.

Postoperatively, CT analysis was performed to assess the spinal fusion. The CT images were examined by two spine surgeons (A and B). Segmental spinal fusion was defined as the presence of complete continuous bony trabeculae across two joint surfaces (Figs. 3, 4). Facet and IBFs were analyzed at 6 and 12 months after the procedure.

Data are presented as mean values and ranges. The inter-observer values were calculated and represented by the kappa value. Statistical analyses were performed using IBM SPSS ver. 20.0 (IBM Corp., Armonk, NY, USA).

\section{Results}

Six consecutive ASD patients were recruited in the study from 2011-2012. The study population included five women and one man, with an average age of 62 years (range, 28 to 72 years) (Tables 1, 2).

The average spinal fusion levels operated on per patient was 11 spinal segments (range, 8 to 15). The preoperative scoliosis Cobb's angle was $25^{\circ}$ (range, $15^{\circ}$ to $43^{\circ}$ ), and the $\mathrm{C} 7$ plumbline was negative $8.4 \mathrm{~cm}$ (range, -12 to $16 \mathrm{~cm}$ ). The mean operative time was 536 minutes (range, 373 to 704 minutes), and the intra-operative blood loss was 975 $\mathrm{mL}$ (range, 500 to $1,800 \mathrm{~mL}$ ). Each patient received a total dose of $12 \mathrm{mg}$ (1 large Infuse kit, Medtronic), with an average dose of $0.69 \pm 0.2 \mathrm{mg}$ (rang, 0.42 to $1 \mathrm{mg}$ ) per single $\mathrm{FF}$ and $1.38 \pm 0.44 \mathrm{mg}$ (range, 0.85 to $2 \mathrm{mg}$ ) for IBF. Local bone grafts were used for all patients.

All six patients, with 88 facets and nine IBFs were ana- 


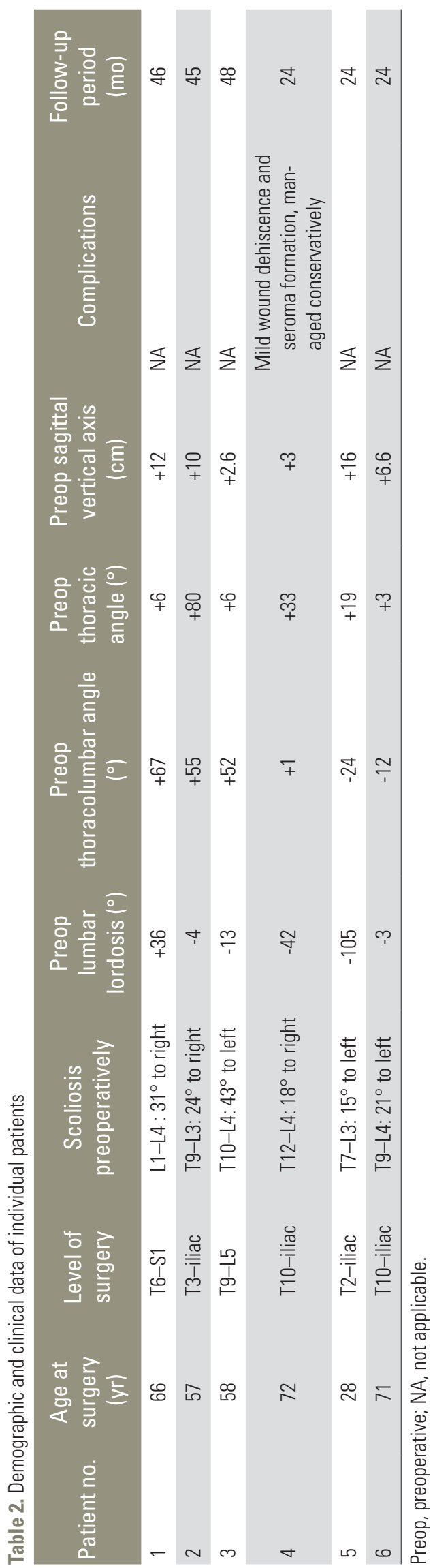

lyzed specifically at 6 months after the procedure. Further, two patients underwent additional longitudinal follow-up CT scans at 12 months, with 43 facets and six IBFs.

At 6 months after the surgery, FF reported by surgeon A was $97.7 \%$, while that reported by surgeon B was $91.9 \%$ $(\kappa=0.95)$. IBF fusion reported by surgeon A was $100 \%$, while that by surgeon B was $100 \%(\kappa=1)$ (Table 3$)$. At 1 year after the procedure, the FF reported by surgeons $A$ and B was $100 \%$ versus $95.8 \%(\kappa=0.96)$. Nine facets were identified to have fusion failure. Five out of nine (56\%) facet non-unions were identified at the cross-links. The remaining four facets were located inferior to the crosslinks, either 1 level distally (two facets) or 2 levels distally (two facets).

The follow-up duration ranged from 64 to 89 months. At the final postoperative clinical follow-up, all patients reported a baseline lower back Visual Analog Scale (VAS) score of 0 (one patient reported occasional mild lower back pain), and lower limb VAS score of 0 .

The clinical outcome scores at the final follow-up were compared to the clinical outcome scores at presentation, and the improvement was calculated. The Oswestry Dis-

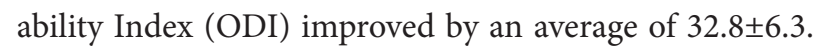
The mental component summary of the 36-item ShortForm Health Survey improved by $4.7 \pm 2.1$, and the physical component summary (PCS) improved by $10.5 \pm 2.1$ at the final follow-up (Table 4).

In a study by Copay et al. [23], the minimum clinically important difference (MCID) for patients who underwent lumbar spine surgery was 12.8 for ODI and 4.9 for PCS. The improvement observed in both the PCS and ODI outcomes scores for the present patients exceeded the MCID.

One patient developed a $4-\mathrm{cm}$ wound dehiscence from a small seroma formation at 2 weeks after the procedure. This was managed conservatively. There were no cases of heterotopic ossification, radiculitis, or osteolysis. No rod breakage, implant failure, or worsening of the spinal deformity was noted. No patient required revision surgery at final follow-up.

\section{Discussion}

While the routine use of RhBMP-2 in single level spinal surgery is controversial, its use in ASD is generally accepted $[18,22,24,25]$. Despite the high success rates in fusion with RhBMP-2, using large doses of RhBMP-2 involves complications $[1,16,17,19,20]$. 
Table 3. Radiological outcome in the study subjects

\begin{tabular}{lcrc} 
Variable & Surgeon A & Surgeon B & K value \\
Facet fusion 6 mo postoperatively & 97.7 & 91.9 & 0.95 \\
Interbody fusion 6 mo postoperatively & 100.0 & 100.0 & 1 \\
Facet fusion 12 mo postoperatively & 100.0 & 95.8 & 0.96 \\
\hline
\end{tabular}

Table 4. Patient's clinical outcome scores

\begin{tabular}{|c|c|c|c|c|c|c|}
\hline Patient no. & $\begin{array}{c}\text { ODI } \\
\text { (preop) }\end{array}$ & $\begin{array}{c}\text { ODI } \\
\text { (final follow-up) }\end{array}$ & $\begin{array}{l}\text { Preop SF } 36 \\
\text { (MCS) }\end{array}$ & $\begin{array}{l}\text { Preop SF36 } \\
\text { (PCS) }\end{array}$ & $\begin{array}{l}\text { Postop SF36 } \\
\text { (MCS) }\end{array}$ & $\begin{array}{l}\text { Postop SF36 } \\
\text { (PCS) }\end{array}$ \\
\hline 1 & 51 & 12 & 39.8 & 24.5 & 45.7 & 36.1 \\
\hline 2 & 48 & 14 & 39.1 & 25.3 & 43.8 & 38.1 \\
\hline 3 & 47 & 13 & 41.9 & 26.7 & 43.6 & 36.4 \\
\hline 4 & 39 & NA & 37.5 & 28.2 & NA & NA \\
\hline 5 & 41 & 17 & 41.9 & 31.1 & 35.6 & 39.1 \\
\hline 6 & 52 & NA & 36.8 & 29.1 & NA & NA \\
\hline
\end{tabular}

ODI, Oswestry Disability Index; Preop, preoperative; SF36, 36-item Short-Form Health Survey; MCS, mental component summary; PCS, physical component summary; Postop, postoperative; NA, not applicable.

The drive in searching for the lowest optimal dose of RhBMP-2 to secure spinal fusion in ASD surgeries is not unfounded. In a systematic review, Chrastil et al. [16] reported post-surgical heterotopic ossification rates ranging from $0 \%-75 \%$, osteolysis rates ranging from $0 \%-100 \%$, and radiculitis rates ranging from $0 \%-100 \%$. RhBMP-2 related complications are dose-dependent [17,21,22]. Devine et al. [17] reported, in a systematic review on five peer-reviewed studies and two Food and Drug Administration safety summaries, that the cancer risk may be dose dependent. Crandall et al. [22] also reported fewer complications with $4 \mathrm{mg}$ RhBMP-2 per disc, with lesser complications of heterotopic ossification as compared to that in patients who underwent fusion at 6-8 mg RhBMP-2 per disc. This is similar to our findings wherein a low dosage of RhBMP-2 corresponded to low complication rates. With the use of $0.69 \mathrm{mg}$ RhBMP-2 for each facet, only one patient demonstrated a possible RhBMP-2-related seroma formation with wound dehiscence that was treated successfully with conservative treatment. At an average final follow-up of 35 months, no patient had heterotopic ossification, osteolysis, radiculitis, implant failure, deformity progression, or required revision surgery.

Failure to achieve spinal fusion can cause pain, neurological complications, and progressive decompensation in the sagittal or the coronal plane of the corrected deformity; this in turn leads to poorer postoperative ODI and Scolio- sis Research Society 24 outcome scores [24-26]. Despite the successful use of RhBMP-2 in increasing the spinal fusion rates, few studies have reported on the lowest dosage of RhBMP-2 required for achieving spinal fusion [1215]. The reported fusion rate with RhBMP-2 ranges from $78 \%$ to $100 \%$ [16]. Crandall et al. [27] reported $99.3 \%$ solid arthrodesis in 872 discs (98.4\%), in patients undergoing transforaminal lumbar IBF. In a comparison of RhBMP-2 with autogenous iliac crest bone graft in ASD surgeries, Kim et al. [26] reported a higher rate of spinal fusion $(93.5 \%$ versus $71.9 \%)$ and a lower rate of pseudoarthrosis $(6.4 \%$ versus 28.1\%). Maeda et al. [28] conducted a 2-year followup to demonstrate that ASD patients in the RhBMP-2 group had a lower pseudarthrosis rate (4.3\%) as compared to patients who underwent ASD surgery with iliac crest bone graft $(28.1 \%)$ in long fusions to the sacrum surgery. They reported the use of an average of $10.0 \mathrm{mg}$ per spinal level for posterior and $11.7 \mathrm{mg}$ per spinal level for anterior surgery [28]. Similarly, Mulconrey et al. [29] reported a successful dorsal spinal fusion rate of $95 \%$ with the use of 10 mg per spinal level of RhBMP-2 in ASD surgery.

In the current study, we used an ultra-low dosage of RhBMP-2, with an average $0.69 \pm 0.2 \mathrm{mg}$ per facet joint and $1.38 \pm 0.44 \mathrm{mg}$ for IBF and achieved an average of $95 \%$ for FF and $100 \%$ for IBF at 6 months after the ASD surgery. Our successful fusion rate may reflect the importance of the FF technique and the possible use of this ultra-low 
dose of RhBMP-2 in ASD surgery.

In this study, the success of spinal fusion was confirmed with CT scan assessment that has superior diagnostic power than radiography-based investigations performed in previous trials [30]. In addition, two individual spinal surgeons independently assessed the CT scan images to reduce the intra-observer errors. Fusion was defined only if continuous bony trabeculae were observed across two joint surfaces. These ensured reliable and accurate fusion assessment results from our analysis. A good interobserver kappa value of 0.95 for FF and 1.00 for IBF was obtained in the CT analysis.

It is noteworthy that five out of nine facets (56\%) that demonstrated fusion failure were found at the cross-link areas, and the remaining four of the nine facets pseudarthrosis were within 1-2 levels caudal to the cross-links. The postulation of fusion failure around the cross-link region may be related to the disturbance in the local bone graft distribution in the facet joint during cross-link application or the presence of the bulky hardware, leading to a false sense of security in achieving successful spinal fusion in the region. Based on the present findings, extra care and more bone grafting is recommended to be performed in the facet joints and the posterolateral area of the spine where the cross-links are applied and in up to 2 levels distal to the cross-links.

One of the limitations of our study is the small sample size. However, in these six ASD patients, total 88 facets and nine IBFs were analyzed specifically at 6 months after the procedure, with two patients undergoing additional longitudinal follow-up CT scans at 12 months, with 43 facets and six IBFs.

In all six patients, 88 facets and nine IBFs were analyzed specifically at 6 months after the procedure. Further, two patients underwent additional longitudinal follow-up CT scans at 12 months, with an additional 43 facets and six IBFs being analyzed. These robust examinations further increase the validity of our findings.

\section{Conclusions}

To the best of our knowledge, this is the first study to report a CT scan-defined $92 \%-98 \%$ FF and 100\% IBF at 6 months after the procedure, using the lowest reported dose of $0.7 \mathrm{mg}$ RhBMP-2 per facet in multilevel ASD surgery. The use of this ultra-low dose RhBMP-2 may result in fewer postoperative complications and reduce the cost of expensive ASD surgeries compared to previously reported methods.

\section{Conflict of Interest}

No potential conflict of interest relevant to this article was reported.

\section{References}

1. De Vries AA, Mullender MG, Pluymakers WJ, Castelein RM, van Royen BJ. Spinal decompensation in degenerative lumbar scoliosis. Eur Spine J 2010;19:1540-4.

2. Oskouian RJ Jr, Shaffrey CI. Degenerative lumbar scoliosis. Neurosurg Clin N Am 2006;17:299-315.

3. Ploumis A, Transfledt EE, Denis F. Degenerative lumbar scoliosis associated with spinal stenosis. Spine J 2007;7:428-36.

4. Schwab F, el-Fegoun AB, Gamez L, Goodman H, Farcy JP. A lumbar classification of scoliosis in the adult patient: preliminary approach. Spine (Phila $\mathrm{Pa}$ 1976) 2005;30:1670-3.

5. Liu G, Tan JH, Ee G, Chan YH, Low SL, Wong HK. Morphology and prevalence study of lumbar scoliosis in 7,075 multiracial Asian adults. J Bone Joint Surg Am 2016;98:1307-12.

6. Deyo RA, Cherkin DC, Loeser JD, Bigos SJ, Ciol MA. Morbidity and mortality in association with operations on the lumbar spine: the influence of age, diagnosis, and procedure. J Bone Joint Surg Am 1992;74:536-43.

7. Yadla S, Maltenfort MG, Ratliff JK, Harrop JS. Adult scoliosis surgery outcomes: a systematic review. Neurosurg Focus 2010;28:E3.

8. Swank S, Lonstein JE, Moe JH, Winter RB, Bradford DS. Surgical treatment of adult scoliosis: a review of two hundred and twenty-two cases. J Bone Joint Surg Am 1981;63:268-87.

9. Buttermann GR, Glazer PA, Hu SS, Bradford DS. Anterior and posterior allografts in symptomatic thoracolumbar deformity. J Spinal Disord 2001;14:54-66.

10. Urist MR. Bone: formation by autoinduction. Science 1965;150:893-9.

11. Wozney JM, Rosen V, Celeste AJ, et al. Novel regulators of bone formation: molecular clones and activities. Science 1988;242:1528-34. 
12. Singh K, Smucker JD, Gill S, Boden SD. Use of recombinant human bone morphogenetic protein-2 as an adjunct in posterolateral lumbar spine fusion: a prospective CT-scan analysis at one and two years. J Spinal Disord Tech 2006;19:416-23.

13. Boden SD, Kang J, Sandhu H, Heller JG. Use of recombinant human bone morphogenetic protein-2 to achieve posterolateral lumbar spine fusion in humans: a prospective, randomized clinical pilot trial: 2002 Volvo Award in clinical studies. Spine (Phila Pa 1976) 2002;27:2662-73.

14. Dimar JR 2nd, Glassman SD, Burkus JK, Pryor PW, Hardacker JW, Carreon LY. Clinical and radiographic analysis of an optimized rhBMP-2 formulation as an autograft replacement in posterolateral lumbar spine arthrodesis. J Bone Joint Surg Am 2009;91:1377-86.

15. Dimar JR, Glassman SD, Burkus KJ, Carreon LY. Clinical outcomes and fusion success at 2 years of single-level instrumented posterolateral fusions with recombinant human bone morphogenetic protein-2/ compression resistant matrix versus iliac crest bone graft. Spine (Phila Pa 1976) 2006;31:2534-9.

16. Chrastil J, Low JB, Whang PG, Patel AA. Complications associated with the use of the recombinant human bone morphogenetic proteins for posterior interbody fusions of the lumbar spine. Spine (Phila Pa 1976) 2013;38:E1020-7.

17. Devine JG, Dettori JR, France JC, Brodt E, McGuire RA. The use of rhBMP in spine surgery: is there a cancer risk? Evid Based Spine Care J 2012;3:35-41.

18. Glassman SD, Howard J, Dimar J, Sweet A, Wilson G, Carreon L. Complications with recombinant human bone morphogenic protein-2 in posterolateral spine fusion: a consecutive series of 1037 cases. Spine (Phila Pa 1976) 2011;36:1849-54.

19. Food and Drug Administration. Summary of safety and effectiveness data (SSED) [Internet]. Silver Spring (MD): Food and Drug Administration; 2010 [cited 2016 Jun 30]. Available from: https://www.accessdata.fda.gov/cdrh_docs/pdf10/P100027b.pdf.

20. Villavicencio AT, Burneikiene S. RhBMP-2-induced radiculitis in patients undergoing transforaminal lumbar interbody fusion: relationship to dose. Spine J 2016;16:1208-13.

21. Mannion RJ, Nowitzke AM, Wood MJ. Promoting fusion in minimally invasive lumbar interbody stabilization with low-dose bone morphogenic protein-2: but what is the cost? Spine J 2011;11:527-33.

22. Crandall DG, Revella J, Patterson J, Huish E, Chang M, McLemore R. Transforaminal lumbar interbody fusion with rhBMP-2 in spinal deformity, spondylolisthesis, and degenerative disease: part 2. BMP dosage-related complications and long-term outcomes in 509 patients. Spine (Phila Pa 1976) 2013;38:1137-45.

23. Copay AG, Glassman SD, Subach BR, Berven S, Schuler TC, Carreon LY. Minimum clinically important difference in lumbar spine surgery patients: a choice of methods using the Oswestry Disability Index, Medical Outcomes Study questionnaire Short Form 36, and pain scales. Spine J 2008;8:968-74.

24. Kim YJ, Bridwell KH, Lenke LG, Cho KJ, Edwards CC 2nd, Rinella AS. Pseudarthrosis in adult spinal deformity following multisegmental instrumentation and arthrodesis. J Bone Joint Surg Am 2006;88:721-8.

25. Kim YJ, Bridwell KH, Lenke LG, Rinella AS, Edwards C 2nd. Pseudarthrosis in primary fusions for adult idiopathic scoliosis: incidence, risk factors, and outcome analysis. Spine (Phila Pa 1976) 2005;30:468-74.

26. Kim HJ, Buchowski JM, Zebala LP, Dickson DD, Koester L, Bridwell KH. RhBMP-2 is superior to iliac crest bone graft for long fusions to the sacrum in adult spinal deformity: 4- to 14-year follow-up. Spine (Phila Pa 1976) 2013;38:1209-15.

27. Crandall DG, Revella J, Patterson J, Huish E, Chang M, McLemore R. Transforaminal lumbar interbody fusion with rhBMP-2 in spinal deformity, spondylolisthesis, and degenerative disease: part 1. large series diagnosis related outcomes and complications with 2- to 9-year follow-up. Spine (Phila Pa 1976) 2013;38:1128-36.

28. Maeda T, Buchowski JM, Kim YJ, Mishiro T, Bridwell $\mathrm{KH}$. Long adult spinal deformity fusion to the sacrum using rhBMP-2 versus autogenous iliac crest bone graft. Spine (Phila Pa 1976) 2009;34:2205-12.

29. Mulconrey DS, Bridwell KH, Flynn J, Cronen GA, Rose PS. Bone morphogenetic protein (RhBMP-2) as a substitute for iliac crest bone graft in multilevel adult spinal deformity surgery: minimum twoyear evaluation of fusion. Spine (Phila Pa 1976) 2008;33:2153-9.

30. Buchowski JM, Liu G, Bunmaprasert T, Rose PS, Riew KD. Anterior cervical fusion assessment: surgical exploration versus radiographic evaluation. Spine (Phila Pa 1976) 2008;33:1185-91. 